IP Periodica Polytechnica

Transportation Engineering

44(4), pp. 201-208, 2016

DOI: $10.3311 /$ PPtr. 8470

Creative Commons Attribution (i)

\title{
H-infinity Backpressure Controller for High Response Engine Exhaust Throttles
}

\author{
Ádám Bárdos ${ }^{1 *}$, Barna Szimandl ${ }^{1}$, Huba Németh ${ }^{1}$
}

Received 04 August 2015; accepted 03 March 2016

\begin{abstract}
Modern engine exhaust restriction valves can be applied not only as retarders. A suitable pressure generation can assist the aftertreatment system (exhaust gas temperature management) and raw emission control as well. To provide these functionalities the exhaust backpressure has to be controlled arbitrarily. In this paper a model-based controller design is demonstrated to minimize calibration effort. A first engineering principle based, mean-value, nonlinear model was described and converted into linear parameter-varying (LPV) form. To satisfy the demands of the above applications the controller needs to be a high dynamic, stabilizing, tracking controller which is robust in the whole relevant engine operation range. The exhaust processes of the individual cylinders generate comparable amplitude pressure oscillations to the expected control accuracy. To fulfill the above requirements and manage the challenge of the exhaust pressure waves an H-infinity controller design method was chosen. In order to handle the saturation of the control signal a high gain anti-windup was applied. Seeking for the lowest possible computational demand the controller order reduction was proposed based on Hankel singular values. Finally the controller performance was demonstrated and evaluated in software-in-the-loop simulations.
\end{abstract}

\section{Keywords}

diesel engines, pressure control, Linear parameter-varying system (LPV), robust control, H-infinity control

\footnotetext{
${ }^{1}$ Department of Automobiles and Vehicle Manufacturing, Faculty of Transportation Engineering and Vehicle Engineering, Budapest University of Technology and Economics, Stoczek u. 6., building J, H-1111 Budapest, Hungary

*Corresponding author, e-mail: adam.bardos@gjt.bme.hu
}

\section{Introduction}

Commercial vehicle wheel brakes are not designed for continuous operation. After permanent application, especially descending with high load downhill, a brake power reduction occurs (widely known as "brake fade") due to the overheating of the frictional surfaces. To avoid it since 1991 buses over a total weight of $5.5 \mathrm{t}$ and trucks over a total weight of $9 \mathrm{t}$ have to be equipped with an additional brake system, which operates independently of the service brake system (Hoepke and Breuer, 2006). On commercial vehicle diesel engines a widely used and cost effective endurance brake is the exhaust brake. These brake retarders are typically designed as butterfly valves and used for generating backpressure for the engine exhaust. The brake power can be increased by generating higher backpressure in the exhaust manifold but its value is limited by the valvetrain design. Consequently the exhaust manifold pressure has to be limited to avoid valvetrain failure. The overpressure limit is engine specific so it is an exhaust brake design parameter. Therefore several exhaust throttle design are required to limit pressure. For example: by means of a hole through the flap or an offsetted flap axle etc. See e.g. (Thompson and Flett, 1994) and (Thompson and Baines, 1995). To fulfill the requirements as endurance brakes, exhaust throttles have only two states: fully opened and fully closed. Nowadays engine exhaust flaps could provide multiple functionality assisting the fulfillment of new requirements driven mainly by the more and more rigorous emission standards. Regulations came into force recently (Euro 6 and US EPA 13) include significant limitations especially on soot and nitrogen-oxides which require the use of an aftertreatment system. To maintain high efficiency in engine exhaust aftertreatment systems it is desirable to avoid cooling by cold exhaust gases in low-load engine conditions and also rapid heating. A controlled exhaust backpressure can be used in this case to accelerate engine heat up and increase exhaust gas temperature at low loads by generating load and decreasing fresh-air charge. In high pressure exhaust gas recirculation systems the exhaust gas mass flow is driven by the pressure difference between the exhaust and intake manifold. The resulting conditions depend on the turbine and compressor 


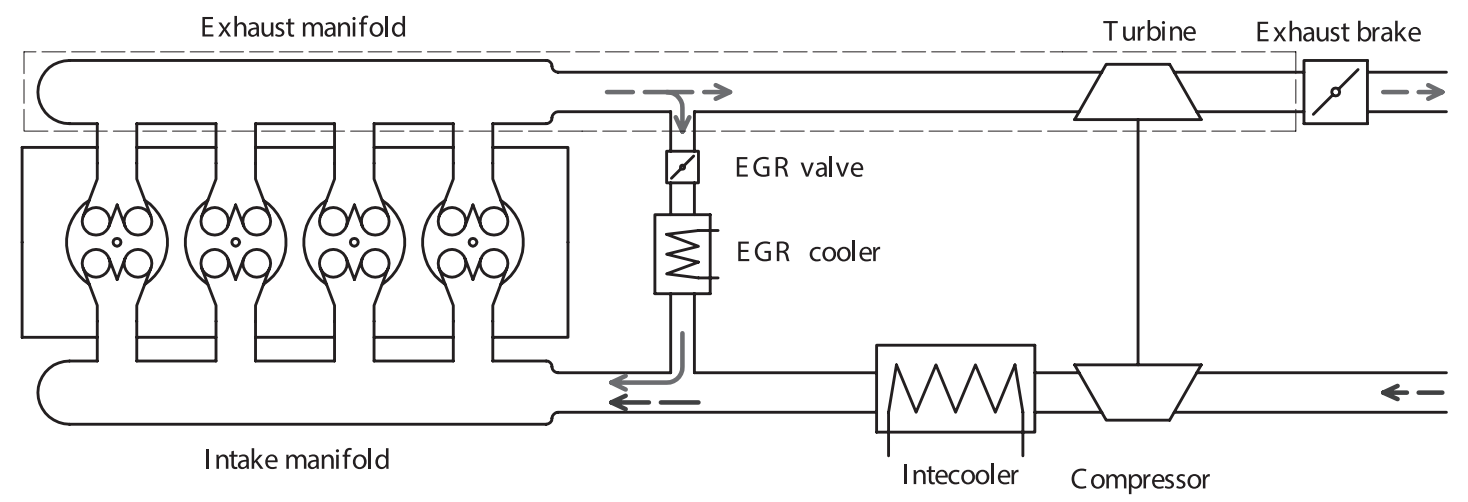

Fig. 1 Layout of the controlled system

characteristics. With an exhaust backpressure controller the pressure drop on the EGR duct can be adjusted and higher recirculated exhaust gas mass flow rates can be reached. With an appropriate control of the engine exhaust manifold pressure the engine brake power can be adjusted arbitrarily. In this way the backpressure controlled exhaust brake operation can substitute a service brake at moderate brake torque demands. This is called brake blending. So the exhaust throttle can be integrated into the service brake operation and can increase the lifetime of brake pads.

This paper deals with a model based exhaust pressure controller design to ensure applicability on different engines and minimize calibration effort. In the next section the engine air path system with the exhaust throttle valve is described. In the third section a first engineering principle based, mean value, nonlinear model is defined which is converted into linear parameter-varying (LPV) form. In Section 4 the pressure oscillation in the exhaust manifold is analyzed which is a challenge of the controller design. In Section 5 the controller synthesis method is demonstrated. The performance is evaluated with simulations on a heavy duty truck six-cylinder engine in Section 6, which leads to the concluding remarks in Section 7.

\section{System description}

The controlled system is a common rail, turbocharged and intercooled diesel engine. The engine was designed with a cooled high-pressure exhaust gas recirculation system (HP-EGR). The exhaust throttle valve was installed directly downstream of the turbine, which provides the minimum volume between the engine exhaust valves and the throttle flap to minimize pressure rise times. The layout of the test engine can be seen in Fig. 1.

\section{Nonlinear and LPV model definition \\ 3.1 Nonlinear state-space model description}

Preliminarily a complete air path model of a diesel engine was validated and published in (Bárdos and Németh, 2013). The model presented below was derived from the referenced work by suitable simplifications.
As balance volume the exhaust manifold was chosen (marked with dashed line in Fig. 1). The effect of the turbocharger turbine was neglected because of the small pressure drop in relevant operation scenarios of the backpressure controller in the engine map such as low load and idle conditions, as consequences of low engine and therefore low turbine mass flow rates. In an exhaust manifold a large heat transfer rate is assumed to take place. In this case the isothermal differential equation for the pressure as state variable is a good approximation as follows:

$$
\frac{d p_{e m}}{d t}=\frac{R_{a i r} \cdot T_{e m}}{V_{e m}} \cdot\left[\sigma_{e o}-\sigma_{e t}-\sigma_{e g r}\right],
$$

where $p_{e m}$ is the exhaust manifold pressure, $R_{\text {air }}$ is the specific gas constant, $T_{e m}$ is the exhaust gas temperature, $V_{e m}$ is the exhaust manifold volume, $\sigma_{e o}, \sigma_{e g r}$ and $\sigma_{e t}$ are the mass flow rates out of the engine, through the EGR valve and through the exhaust throttle respectively. The exhaust gas recirculation valve in the above mentioned typical operation range of the backpressure controller is usually closed so $\sigma_{\text {egr }}$ was neglected.

The exhaust gas mass flow rate is the sum of the engine intake gases and the injected fuel quantity:

$$
\sigma_{e o}=\sigma_{e i}+\sigma_{\text {fuel }} \text {. }
$$

Due to high amount of excess air the fuel mass flow rate is relative small compared to the intake air, especially at low engine loads. So $\sigma_{\text {fuel }}$ was treated as zero. Therefore the use of the specific gas constant of the air as well as a constant exhaust gas temperature is a good simplification.

The engine can be modeled as a positive displacement pump so the induced gas mass flow rate into the cylinders is formulated in the following form:

$$
\sigma_{e i}=\eta_{v o l} \cdot \varrho_{i m} \cdot n_{e} \cdot \frac{V_{d}}{i}=\eta_{v o l} \cdot \frac{p_{i m}}{R_{\text {air }} \cdot T_{i m}} \cdot n_{e} \cdot \frac{V_{d}}{i},
$$

where $\eta_{v o l}$ is the volumetric efficiency, $\varrho_{i m}$ is the intake air density, $n_{e}$ is the engine speed, $V_{d}$ is the engine displacement, $i$ is the number of revolutions per cycle, $p_{i m}$ is the boost pressure, $T_{i m}$ is the boost temperature. 
The engine volumetric efficiency was treated as a constant which is a good approximation for a commercial vehicle diesel engine due to the narrow engine speed range.

The mass flow through the exhaust throttle valve can be calculated with the standard orifice equation based on (Guzzella and Onder, 2010):

$$
\sigma_{e t}=c_{d, e t} \cdot A_{e t}\left(\varphi_{e t, a c t}\right) \cdot \frac{p_{e m}}{\sqrt{R_{\text {air }} \cdot T_{e m}}} \cdot \Psi\left(\frac{p_{e m}}{p_{a m b}}\right),
$$

where $c_{d, e t}$ is the discharge coefficient, $A_{e t}\left(\varphi_{e t, a c t}\right)$ is the geometrical area of the exhaust flap, which is a function of the actual flap position.

The flow function $\Psi\left(\frac{p_{e m}}{p_{a m b}}\right)$ is defined depending on the flow conditions for $p_{a m b}<p_{c r}$ :

$$
\Psi\left(\frac{p_{e m}}{p_{a m b}}\right)=\sqrt{\kappa\left(\frac{2}{\kappa+1}\right)^{\frac{\kappa+1}{\kappa-1}}}
$$

and for $p_{a m b} \geq p_{c r}$ :

$$
\Psi\left(\frac{p_{e m}}{p_{a m b}}\right)=\left(\frac{p_{e m}}{p_{a m b}}\right)^{\frac{1}{\kappa}} \cdot \sqrt{\frac{2 \kappa}{\kappa-1} \cdot\left[1-\left(\frac{p_{a m b}}{p_{e m}}\right)^{\frac{\kappa-1}{\kappa}}\right]},
$$

where $\kappa$ is the adiabatic exponent, $p_{a m b}$ is the ambient pressure.

The critical pressure can be calculated as:

$$
p_{c r}=\left[\frac{2}{\kappa+1}\right]^{\frac{\kappa}{\kappa-1}} \cdot p_{e m} .
$$

The geometrical area of a butterfly valve in function of the shaft position is nonlinear. Approximation formulas can be found in (Heywood, 1988). As a consequence of the nonlinear behavior of the system the geometrical area of the throttle valve is only relevant in the range of fully closed flap positions. In this region the throttle area as a function of the throttle flap position can be approximated with a linear expression as defined below:

$$
A_{e t}\left(\varphi_{e t, a c t}\right)=A_{e t, 0}-A_{e t, 0} \cdot \varphi_{e t, a c t}+A_{\text {leak }},
$$

where $A_{e t, 0}$ is the geometrical area of the fully opened throttle valve and $A_{\text {leak }}$ is the leakage area of the fully closed flap.

As can be seen the system behavior is not continuous due to the valve mass flow dependence on the flow conditions. To define the model as compact as possible a nominal hybrid mode was chosen in order to obtain a unique model structure. The backpressure controller operates mostly at sonic flow speeds so according to the nominal hybrid mode the mass flow through the valve is:

$$
\sigma_{e t}=c_{d, e t} \cdot\left(A_{e t, 0}-A_{e t, 0} \cdot \varphi_{e t, a c t}\right) \cdot \frac{p_{e m}}{\sqrt{R_{a i r} \cdot T_{e m}}} \cdot \sqrt{\kappa\left(\frac{2}{\kappa+1}\right)^{\frac{\kappa+1}{\kappa-1}}} .
$$

Due to its comparable rise times with the balance volume pressure rise time the inclusion of the actuator dynamics is inevitable. It was defined as a first order lag in the following form:

$$
\frac{d \varphi_{e t, a c t}}{d t}=-\frac{1}{T_{e t}} \varphi_{e t, a c t}+\frac{1}{T_{e t}} \varphi_{e t, d e m},
$$

where $T_{e t}$ is the time constant and $\varphi_{e t, d e m}$ is the position demand.

For controller design the model was written in state space form as:

$$
\frac{d \mathbf{x}}{d t}=\mathbf{f}(\mathbf{x}, \mathbf{d})+\mathbf{g}(\mathbf{x}, \mathbf{d}) \mathbf{u},
$$

where the state vector is:

$$
\mathbf{x}=\left[\mathrm{p}_{\mathrm{em}}, \varphi_{\mathrm{et}, \mathrm{act}}\right]^{T} \in \mathbb{R}^{2},
$$

the input vector is the throttle valve position demand:

$$
\mathbf{u}=\left[\varphi_{\mathrm{et}, \mathrm{dem}}\right] \in \mathbb{R},
$$

the measurable disturbance vector is:

$$
\mathbf{d}=\left[\mathrm{n}_{\mathrm{e}}, \mathrm{p}_{\mathrm{im}}\right]^{T} \in \mathbb{R}^{2} .
$$

With the above defined notations the state space model can be defined as followings:

$$
\left[\begin{array}{c}
\dot{\mathrm{p}}_{\mathrm{em}} \\
\dot{\varphi}_{\text {et }, a c t}
\end{array}\right]=\left[\begin{array}{c}
f_{1}(\mathbf{x}, \mathbf{d}) \\
f_{2}(\mathbf{x}, \mathbf{d})
\end{array}\right]+\left[\begin{array}{c}
g_{1}(\mathbf{x}, \mathbf{d}) \\
g_{2}(\mathbf{x}, \mathbf{d})
\end{array}\right]\left[\varphi_{\mathrm{et}, \mathrm{dem}}\right],
$$

$$
\begin{aligned}
f_{1}(\mathbf{x}, \mathbf{d})=\frac{R_{\text {air }} \cdot T_{e m}}{V_{e m}} & \cdot\left[\eta_{\text {vol }} \cdot \frac{p_{i m}}{R_{\text {air }} \cdot T_{i m}} \cdot n_{e} \cdot \frac{V_{d}}{i}\right. \\
- & c_{d, e t} \cdot\left(A_{e t, 0}-A_{e t, 0} \cdot \varphi_{e t, a c t}+A_{\text {leak }}\right) \\
& \left.\cdot \frac{p_{e m}}{\sqrt{R_{\text {air }} \cdot T_{e m}}} \cdot \sqrt{\kappa\left(\frac{2}{\kappa+1}\right)^{\frac{\kappa+1}{\kappa-1}}}\right],
\end{aligned}
$$

$$
g_{1}(\mathbf{x}, \mathbf{d})=0
$$

$$
\begin{gathered}
f_{2}(\mathbf{x}, \mathbf{d})=-\frac{1}{T_{e t}} \varphi_{e t, a c t}, \\
g_{2}(\mathbf{x}, \mathbf{d})=\frac{1}{T_{e t}} .
\end{gathered}
$$

The measured and performance outputs are respectively:

$$
\begin{gathered}
\mathbf{y}=\left[\begin{array}{cc}
\varphi_{e t, a c t}, & p_{e m}
\end{array}\right]^{T} \in \mathbb{R}^{2}, \\
\mathbf{z}=\left[p_{e m}\right] \in \mathbb{R} .
\end{gathered}
$$




\subsection{Conversion into linear parameter-varying state space model}

To design an H-infinity controller which can handle the nonlinear behavior of the system in the whole engine map and guarantee robustness the linear parameter-varying state space model is a suitable form. This structure was successfully applied in diesel engine air path modeling e.g. see (Jung and Glover, 2003). H-infinity controller synthesis can be specified with separated actuator dynamics from the controlled plant. Therefore only the first state equation in (15) was converted into the LPV form.

$$
\begin{aligned}
\frac{d p_{e m}}{d t}= & \frac{R_{a i r} \cdot T_{e m}}{V_{e m}} \cdot \eta_{v o l} \cdot \frac{p_{i m}}{R_{a i r} \cdot T_{i m}} \cdot n_{e} \cdot \frac{V_{d}}{i} \\
& -\frac{R_{a i r} \cdot T_{e m}}{V_{e m}} \cdot c_{d, e t} \cdot A_{e t} \cdot \frac{p_{e m}}{\sqrt{R_{a i r} \cdot T_{e m}}} \cdot \sqrt{\kappa\left(\frac{2}{\kappa+1}\right)^{\frac{\kappa+1}{\kappa-1}}} .
\end{aligned}
$$

The linear conversion from the flap valve position to the valve area can be calculated by an algebraic function. Seeking the simplest model structure as an input the throttle area was chosen $\left(\mathbf{u}=\left[A_{e t}\right]\right)$. A review of Eq. (22) reveals that only the exhaust manifold pressure enters the state equation in a nonlinear way. Therefor it has been considered as a parameter: $\varrho=p_{e m}$. The boost pressure and the engine speed are measurable disturbance inputs to the plant which multiply the first part of Eq. (22). Therefore they have been defined the product: $\mathbf{w}=\left[p_{i m} \cdot n_{e}\right]$. So the model was defined in the following form:

$$
\frac{d \mathbf{x}}{d t}=\mathbf{A}(\rho) \mathbf{x}+\mathbf{B}_{1}(\rho) \mathbf{w}+\mathbf{B}_{2}(\rho) \mathbf{u},
$$

in which the parameter dependent matrices are given as:

$$
\begin{gathered}
\mathbf{A}(\rho)=[0] \\
\mathbf{B}_{1}(\rho)=\left[\frac{T_{e m}}{V_{e m} \cdot T_{i m}} \cdot \eta_{v o l} \cdot \frac{V_{d}}{i}\right] \\
\mathbf{B}_{2}(\rho)=\left[-\frac{R_{a i r} \cdot T_{e m}}{V_{e m}} \cdot c_{d, e t} \cdot \frac{\varrho}{\sqrt{R_{a i r} \cdot T_{e m}}} \cdot \sqrt{\kappa\left(\frac{2}{\kappa+1}\right)^{\frac{\kappa+1}{\kappa-1}}}\right] .
\end{gathered}
$$

Note that the A matrix is equal to zero because the state variable was considered as a parameter so a quasi-LPV model was specified. The performance output:

$$
\mathbf{z}(t)=C_{11} \mathbf{x}+D_{11}(\rho) \mathbf{w}+D_{12}(\rho) \mathbf{u} .
$$

The measured output:

$$
\mathbf{y}(t)=C_{21} \mathbf{x}+D_{21}(\rho) \mathbf{w}+D_{22}(\rho) \mathbf{u} .
$$

So the state space matrices become:

$$
\mathbf{C}=\left[\begin{array}{l}
1 \\
1
\end{array}\right] ; \quad \mathbf{D}=\left[\begin{array}{ll}
0 & 0 \\
0 & 0
\end{array}\right]
$$

\section{Pressure fluctuations in the exhaust manifold}

The above nonlinear and LPV state-space model is a meanvalue model. The exhaust gas mass flow out of the cylinders was considered as a constant flow from one single source. In fact, the exhaust stroke of individual cylinders is shifted in time and the mass flow rate from the exhaust valves changes in a wide range. In this way periodic pressure oscillations (even 0.5 bar amplitude) arise in the exhaust manifold which can be compared to the expected accuracy of the backpressure controller. This exhaust frequency, namely the Engine Firing Rate (EFR), can be calculated with the following formula. For details see (Shah et al., 2010).

$$
E F R=\frac{n_{e}}{i} \cdot z,
$$

where $z$ is the number of engine cylinders. Based on vehicle measurements a power spectral density plot were made at different engine speeds, which is depicted below.

It can be seen in Fig. 2 that the measurement returns the expected base harmonics frequencies calculated by Eq. (30). It can also be seen that the magnitude of the higher order harmonics is neglectable (except at 700 RPM). The highest power spectral density values are reached at 1800 RPM and 2000 RPM. Note that their magnitude values are depicted divided by six and three to ensure readability. The above described nonlinear model was linearized with the Jacobian method around a typical operation point: 1500 RPM (the engine speed range is between 700 and 2000 RPM and this speed is frequently used during the operation of the backpressure controller) $p_{e m}=3 \mathrm{bar}$ and $\varphi_{e t, a c t}=92 \%$. The Bode plot of the system can be seen on Fig. 3. The cut-off frequency of the plant is $230 \mathrm{~Hz}$ (marked with arrow). Therefore the system dynamics overlap the excitation frequencies of the pressure oscillations. Thus it cannot be filtered so a rejection of the pressure oscillations effect of the control input signal is needed. The proposed controller which can handle this problem is described in the following section.

\section{Control design}

\subsection{Control aims and requirements}

The control requirements which must be fulfilled by the engine exhaust backpressure controller were initially laid down as follows:

$\mathcal{R} 1$. A stabilizing controller is needed at every engine operation point and condition that can occur in the presence of model uncertanties and disturbances.

$\mathcal{R} 2$. Easy applicability and low calibration effort on various engines. 


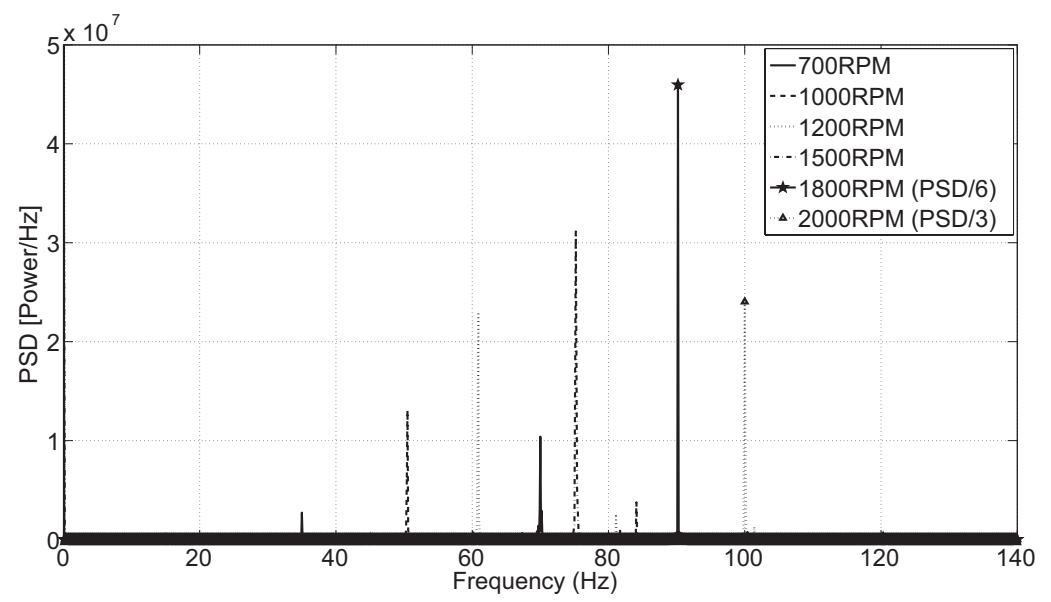

Fig. 2 Exhaust pressure power spectral density plot at different engine speeds

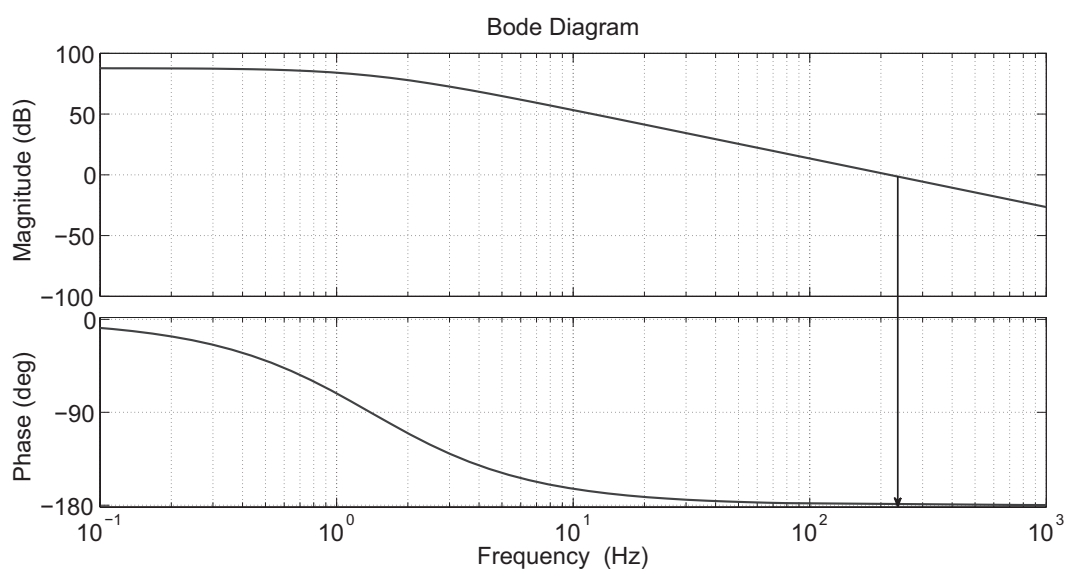

Fig. 3 Bode plot of the linearized model

$\mathcal{R} 3$. The overshoots should be below 0.2 bars to avoid potential engine damage caused by a too high backpressure level.

$\mathcal{R} 4$. The steady state error must be below 0.2 bars.

$\mathcal{R} 5$. The closed loop system response time must be as close as possible to the open loop system response time.

$\mathcal{R} 6$. The control activity must be minimized to avoid damage to the bearings of the flap valve as well as actuator drive mechanism failure.

$\mathcal{R} 7$. The actuator saturation must be adequately handled by the controller.

$\mathcal{R} 8$. The complexity of the control algorithm should be low enough to allow its application in an embedded environment, where the clock rate of the applied single core processor is in the range of $40-50 \mathrm{kHz}$ and the available memory is below 64 kbyte.

\subsection{H-infinity controller synthesis}

A two degree of freedom closed loop interconnection system was considered for the formulation of the H-infinity controller synthesis problem based on the suggestions in (Szimandl and Németh, 2014) and (Bokor et al., 2012). The structure is depicted in the figure below, where $r$ denotes the reference input, $u$ is the control input, and $z_{e}$ is the performance output. The structure of the controller includes the $K_{y}$ feedback and $K_{r}$ pre-filter part, so the controller made up of two parts as $K=\left[\begin{array}{ll}K_{r} & K_{y}\end{array}\right]$

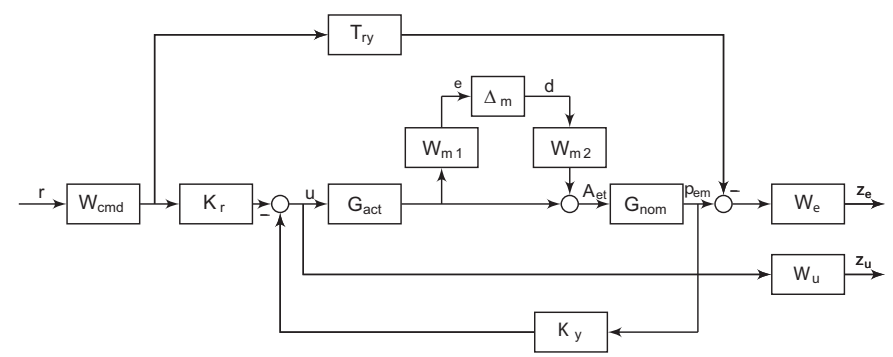

Fig. $4 H_{\infty}$ controller design structure

Although the pressure waves from the exhaust processes of the cylinders are in fact non-modeled dynamics of the plant, the effect of these pressure waves can be treated as a disturbance on the output of the plant. Therefore its effect on the control input is parametrized by the controller as $\mathbf{u}=\mathbf{K S}_{0} \mathbf{d}=\mathbf{K}(\mathbf{I}+\mathbf{P K})^{-1} \mathbf{d}$. For details see (Zhou et al., 1996) and (Bárdos et al., 2014). So the controller must be synthesized with the minimal gain from the $p_{e m}$ to the control input in the frequency region of the 
possible EFR. To avoid high control activity and potential actuator and flap mechanism damages the actuator weighting function was chosen as a third order high pass Butterworth filter with a cut off frequency of $30 \mathrm{~Hz}$ as follows: $W_{u}=\frac{10 \cdot s^{3}}{s^{3}+377 \cdot s^{2}+7 \cdot 11 e 4 \cdot s+6.7 e 6}$. The required transfer function from the reference to the exhaust manifold pressure has been defined as a first order transfer function: $\quad T_{r y}=\frac{1}{1 /(5 \cdot 2 \cdot \pi) \cdot s+1} . \quad W_{c m d}$ describes the magnitude and the frequency dependence of the reference command generated by the normalized reference signal $r$. Allowing a step reference input and targeting a maximum backpressure of 5 bars constant transfer function $W_{c m d}=5 \cdot 10^{5}$ was defined. The actuator dynamics were treated as a first order transfer function as defined above: $G_{a c t}=\frac{1}{0.025 \cdot s+1}$. The input multiplicative uncertainty $W_{m 1}=\frac{0.2 s}{s+188.5}$ and $W_{m 2}=0.003$ model was applied to deal with the unmodeled dynamics (mainly the exhaust pressure oscillation) of the plant, resulting in $20 \%$ uncertainty at frequencies above $30 \mathrm{~Hz}$. In order to meet requirements to keep steady state errors below 0.2 bars the performance output weighting function was defined as $W_{e}=\frac{1}{0.2+10^{5}} \cdot \frac{1}{159.15 \cdot s+1}$. To derive the robust performance of the closed loop system and synthesize the controller the above structure was reformulated in the LFT form. In this way the so-called $\Delta-P-K$ structure was reached as depicted in Fig. 5.

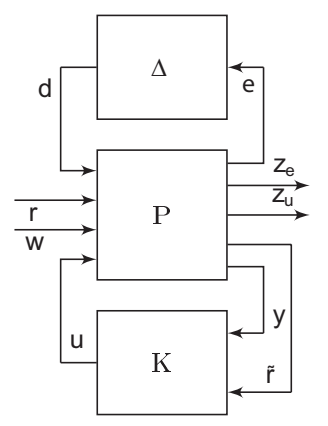

Fig. $5 \Delta-P-K$ structure for controller design
Using the weighting functions of the nominal performance and the robust stability specifications a sub-optimal $H_{\infty}$ controller was designed. With the 2-Riccati solution method an 8th order controller was reached with $\gamma=0.995$. In order to meet the requirements and design the lowest possible order controller the Hankel singular value based order reduction procedure was applied. The lowest order controller which showed no appreciable performance deviance from initial 8th order controller was 5 th order. Figure 6 shows the resulted controller transfer function from the exhaust manifold signal to the control input. Note that in the critical frequency region of the pressure oscillations (possibly EFR frequency region) a suppression occurs.

To reject the effect of the measurable disturbance the following feedforward control was specified:

The controller was implemented with the algebraic linear function

$$
u_{f f}=\frac{\mathbf{B}_{1}(\rho)}{\mathbf{B}_{2}(\rho)} \mathbf{w}
$$

as depicted in Fig. 7. It ensures the conversion from the throttle area to the actuator position demand.

$$
f(A)=\varphi_{e t, a c t}=\frac{-A_{e t}+A_{e t, 0}+A_{\text {leak }}}{A_{e t, 0}}
$$

\subsection{Saturation handling}

In order to handle the saturation of the throttle valve actuator a high gain anti-windup was applied similar to (Szimandl and Németh, 2014) and (Kothare et al., 1994). The anti-windup compensation is provided by subtracting the difference between the actual and the saturated control signals through a high gain matrix to the controller input.

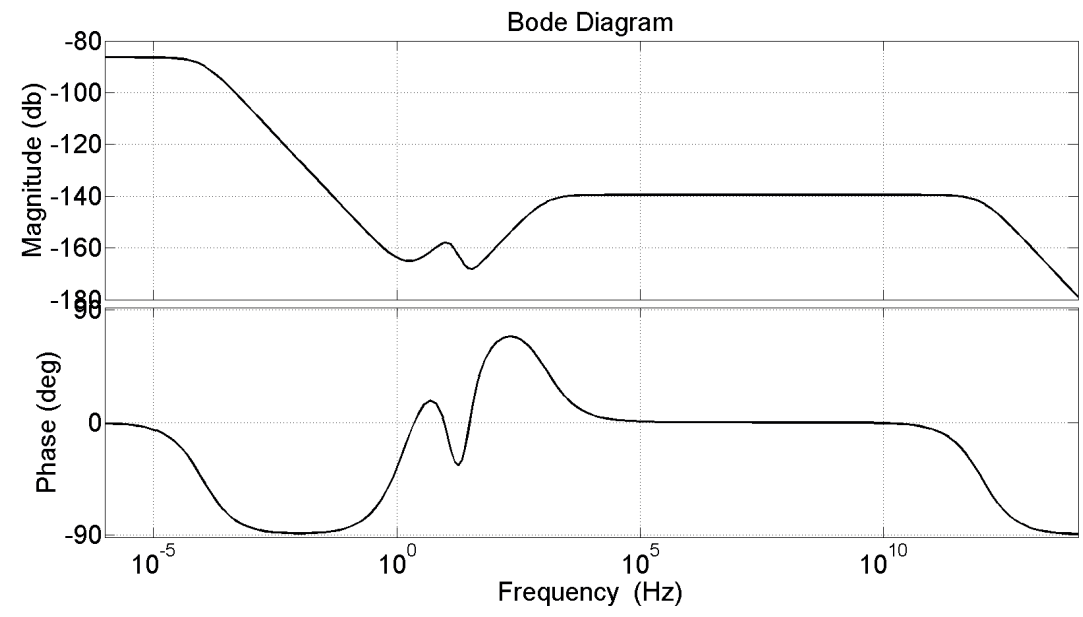

Fig. 6 Controller transfer function from $p_{e m}$ to control input 


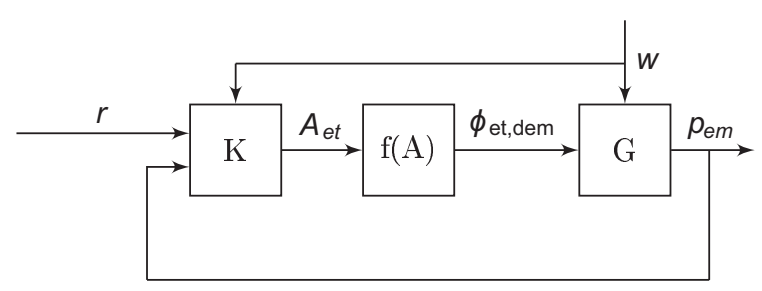

Fig. $7 H_{\infty}$ control structure

\subsection{Controller performance evaluation}

To evaluate the controller performance the reduced 5th order controller was implemented in MATLAB/Simulink environment in discrete time with $1 \mathrm{~ms}$ sample time and numerical simulations were carried out. 1500 RPM engine speed and 1 bar boost pressure was adjusted as a frequently used engine operation point during exhaust backpressure generation. The test sequence contains a step of the maximum 5 bar backpressure to evaluate the settling time and 0.5 bar steps up and down to check the overshoot/undershoot behavior of the system and accuracy. The test results can be seen in Fig. 8 .

A pressure oscillation was measured in a real engine and, after extracting its mean value, it was added to the simulated meanvalue exhaust manifold pressure signal. This "noisy" signal was lead to the controller to accurately simulate a real engine. It can be seen that the backpressure signal settles without steady-state error and without over or undershoot. The pressure rise follows the preliminarily prescribed first order behavior. The effect of the pressure oscillation still disturbs the control input signal, but due to the rejection effect of the controller transfer function in the relevant region (see Fig. 6) the peak to peak steady state actuator demand chattering is below $8 \%$.

\section{Conclusion}

This paper deals with a linear parameter-varying (LPV) model based H-infinity control of commercial vehicle diesel engines exhaust backpressure. The motivation of this work is the possible new applications of backpressure controlled exhaust throttle valves, e.g.: brake blending, exhaust gas temperature management, exhaust gas recirculation (EGR) support. A second order control-oriented, nonlinear model was derived and converted in LPV state-space form. One system state, the exhaust manifold pressure was considered as scheduling variable. The model input is the throttle area which is converted by a linear function to throttle position demand which is the input of the actuator. Caused by the exhaust processes of the individual cylinders pressure oscillations arises in the exhaust manifold signal. The amplitudes of the pressure waves are comparable to the expected accuracy. The oscillation frequency is overlapped by the system cut-off frequency which was a challenge through the controller design. Based on the LPV model a 8th order H-infinity controller was synthesize. The controller order was reduced to 5 by Hankel singular value based model reduction to meet low computational demand requirements. To handle actuator saturation a high gain anti-windup was applied. Controller performance was tested in a software-in-the-loop (SIL) test which demonstrates the fulfillment of almost every preliminary requirements and the rejection of the pressure waves effect, modest control activity. Nevertheless $\mathcal{R} 8$ can hardly be fulfilled at the present level of controller complexity despite of the controller order reduction procedure.
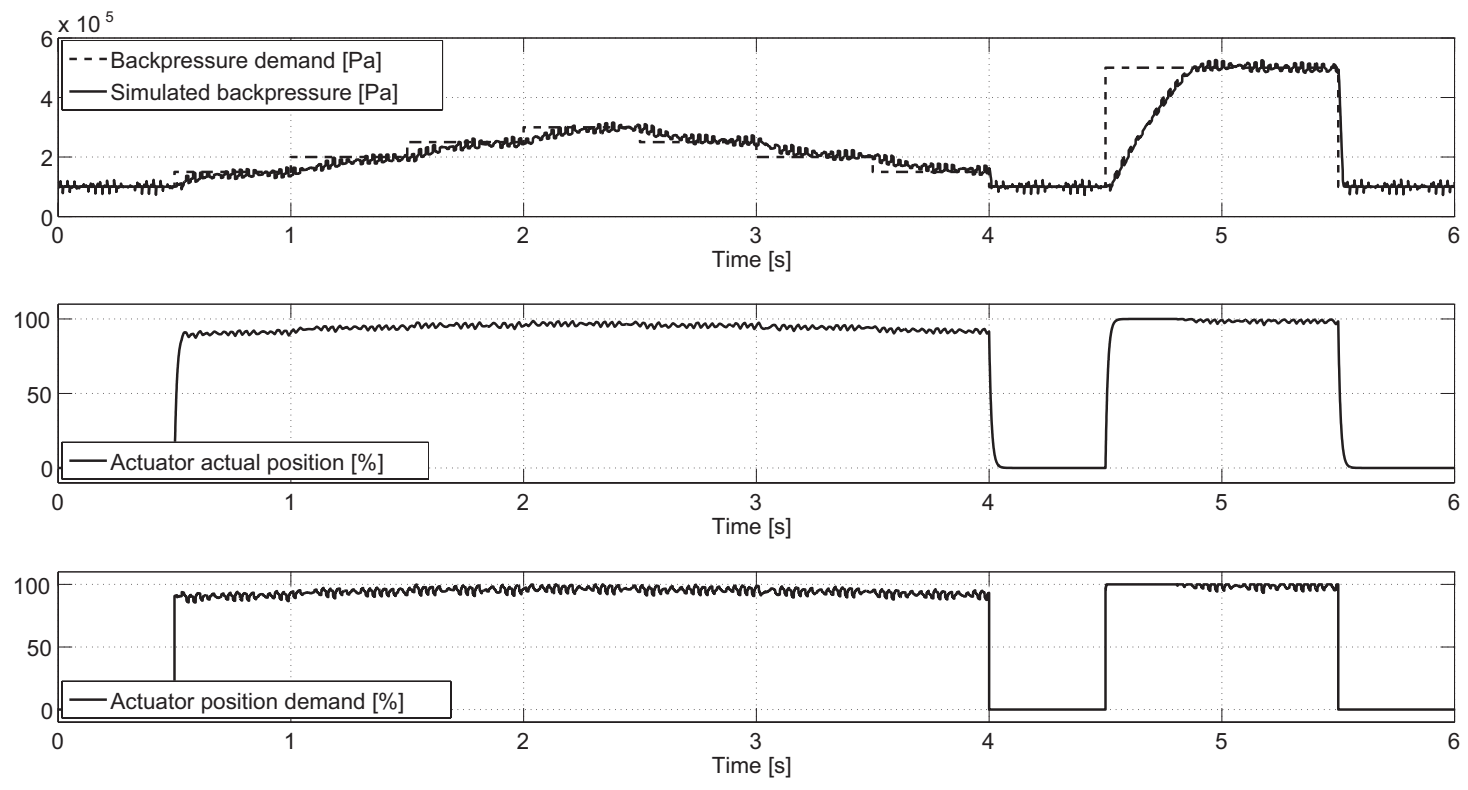

Fig. 8 Controller performance during a test cycle 


\section{References}

Bárdos, Á., Németh, H. (2013) Control oriented air path model for compressed air boosted diesel engines. Periodica Polytechnica Transportation Engineering. 41(1), pp. 3-12. DOI: 10.3311/PPtr.7093

Bárdos, Á., Szimandl, B., Németh, H. (2015) Feedforward LQ servo backpressure controller for engine exhaust throttle. In: Proceedings of the 14th mini conference on vehicle system dynamics, identification and anomalies: VSDIA 2014. Budapest, Hungary, Nov. 10-12, 2014. pp. 437-444.

Bokor, J., Gáspár, P., Szabó, Z. B. (2012) Robust control theory with automotive applications. Typotex Kiadó, Budapest.

Guzzella, L., Onder, C. H. (2010) Introduction to modeling and control of internal combustion engine systems. 2nd Edition. Springer-Verlag, Berlin, Heidelberg. DOI: 10.1007/978-3-642-10775-7

Heywood, B. J. (1988) Internal Combustion Engine Fundamentals. McGrawHill, Inc., New York.

Hoepke, E., Breuer, S. (eds.) (2006) Nutzfahrzeugtechnik: Grundlagen, Systeme, Komponenten. Friedrich Vieweg and Sohn Verlag, Wiesbaden. (in German)

Jung, M., Glover, K. (2003) Control-oriented linear parameter-varying modelling of a turbocharged diesel engine. In: Proceedings of 2003 Conference on Control Applications, CCA 2003. Istanbul, Turkey, June 23-25, 2003. pp. 155-160. DOI: 10.1109/CCA.2003.1223282
Kothare, M. V., Campo, P. J., Morari, M., Nett, C. N. (1994) A unified framework for the study of anti-windup designs. Automatica. 30(12), pp. 1869-1883. DOI: 10.1016/0005-1098(94)90048-5

Shah, S., Kuppili, S., Hatti, K., Thombare, D. (2010) A practical approach towards muffler design, development and prototype validation. SAE Technical Paper, 2010-32-0021. DOI: 10.4271/2010-32-0021

Szimandl, B., Németh, H. (2014) Robust servo control design for an electropneumatic clutch system using the H-infinity method. In: Mechatronic and Embedded Systems and Applications (MESA), 2014 IEEE/ASME 10th International Conference on. Ancona, Italy, Sept. 10-12, 2014. pp. 1-6. DOI: 10.1109/MESA.2014.6935526

Thompson, D., Baines, R. G. (1995) Exhaust pressure modulation valve. US5394901 patent, 1995-03-07. URL: https://www.google.com/ patents/US5394901

Thompson, D., Flett, M. E. (1994) Exhaust brake and pressure modulation valve. EP0578373 patent, 1994-01-12. URL: https://www.google.com/ patents/EP0578373A1?cl=en

Zhou, K., Doyle, J. C., Glover, K. (1996) Robust and Optimal Control. Prentice-Hall, Inc., Upper Saddle River, NJ, USA. 